\title{
Cultured Meat: Promises and Challenges
}

\author{
Nicolas Treich $^{1}$ (D)
}

Accepted: 8 March 2021 / Published online: 19 March 2021

(c) The Author(s), under exclusive licence to Springer Nature B.V. 2021

\begin{abstract}
Cultured meat involves producing meat from animal cells, not from slaughtered animals. This innovation has the potential to revolutionize the meat industry, with wide implications for the environment, health and animal welfare. The main purpose of this paper is to stimulate some economic research on cultured meat. In particular, this paper includes a prospective discussion on the demand and supply of cultured meat. It also discusses some early results on the environmental impacts of cultured meat, emphasizing the promises (e.g., regarding the reduction in land use) but also the uncertainties. It then argues that cultured meat is a moral improvement compared to conventional meat. Finally, it discusses some regulatory issues, and the need for more public support to the innovation.
\end{abstract}

Keywords Meat - Cultured meat · Food innovation · Meat consumption · Meat production · Climate change $\cdot$ Pollution $\cdot$ Land use $\cdot$ Animal welfare $\cdot$ Regulation

JEL Classification Q16·Q18·Q52 -Q11 $\cdot \mathrm{L} 31 \cdot \mathrm{L} 66$

\section{Introduction}

Cultured meat ${ }^{1}$ involves the production of meat outside of the animal and in vitro (Post et al. 2020). Specifically, cultured meat is produced from animal cells cultured in a growth medium in a bioreactor rather than being directly sourced from slaughtered animals. Cultured meat is therefore produced in a radically different way compared to conventional livestock methods. The idea of producing meat in vitro has long been advocated by scientists, politicians and artists. This idea is now becoming a technical reality, as cultured meat has just started to be commercialized. ${ }^{2}$ Dozens of companies are currently working to develop and bring their product to the market in the coming years (Rubio et al. 2020).

\footnotetext{
1 There exist other names for cultured meat such as 'in vitro meat', 'clean meat', 'cell-based meat', 'cellcultured meat', 'lab-grown meat', 'synthetic meat', 'Frankenstein meat', or more recently, 'cultivated meat'. Note that all names include the term 'meat'.

2 The Singapore Food Agency authorized the commercialization of the Eat Just's cultured chicken in December 2020. This is the first authorization of cultured meat by a regulatory safety agency.
}

Nicolas Treich

nicolas.treich@inrae.fr

1 Toulouse School of Economics, INRAE, University Toulouse Capitole, Toulouse, France 
Cultured meat is a technical revolution, but it is also a possible economic and societal revolution, with the potential to disrupt the traditional meat sector. Given that animal agriculture uses more than three-quarters of the world's agricultural land (Foley et al. 2011; Poore and Nemecek 2018), cultured meat can readily reshape the world as we know it. It can address several environmental issues, such as air, soil and water pollution posed by traditional agriculture (Tuomisto and Teixeira de Mattos 2011; Poore and Nemecek 2018). It can also drastically reduce the risks of emerging infectious diseases, which are principally associated with the storage, production and consumption of animal food (Espinosa et al. 2020). Since cultured meat can be produced indoors during unfavorable external conditions, such as natural disasters, it may lower global food insecurity. And since it is produced under sterile conditions, it can virtually eliminate contamination with disease-causing pathogens (Rubio et al. 2020). Further, cultured meat does not rely on the exploitation and slaughter of animals, and thus has strong moral implications.

Although the potential benefits of cultured meat are considerable, there remain wide uncertainties. Consider, for instance, the argument that this innovation can significantly reduce the cost of producing meat, along with its associated environmental externalities. This argument seems sensible at first: the production of cultured meat does not require all the resources to raise and maintain a farm animal alive. However, there is an opposing argument: muscle development has evolved over millions of years within the body of animals, and producing muscle differently may be costly and inefficient in terms of resource use. Indeed, a large amount of energy is required to produce the ingredients for the growth medium and for running the bioreactor (e.g., for temperature control, aeration and the mixing processes).

The main objective of this paper is modest; to initiate a consideration of the economics of cultured meat. The current economic literature on this topic is essentially nonexistent. Therefore, we gather our knowledge from different sources-mostly outside of economics-and try to present it in such a way that could be useful to economists who may be interested in further study. Given the uncertainty inherent in the novelty of this technology, the paper is explorative rather than predictive. Given, also, the rate of progress of knowledge on this issue, it may likely become rapidly out-of-date. ${ }^{3}$

However, we believe that it is useful to start a reflection on several basic economic questions, such as the following: Can cultured meat become globally beneficial? What are its possible major economic, environmental, health, and moral impacts? How will cultured meat be produced, and by whom? How will consumers and the conventional meat sector react? What action should regulators take? Where are the main uncertainties? We will briefly discuss each of these questions, in the hope that this paper may-at the very least-encourage an emerging body of economic research. We believe in particular that this topic is very relevant for environmental economists, as the novel food generates high promises for the environment. Moreover, the complexity of the topic mixing agriculture, food, land use, climate as well as energy issues calls for more integrated research involving economists.

The outline of the paper is as follows. We first present issues regarding the externalities of conventional meat and the need to find solutions, in Sect. 2. In Sect. 3, we present a brief history and summary of cultured meat research and development. Thus, Sects. 2 and 3 provide some context before addressing the economic issues, and can easily be skipped by

3 This paper was written in 2020, and revised in early 2021. 
readers familiar with the topic. We discuss some demand side issues in Sect. 4, and some supply side issues in Sect. 5. We then discuss environmental issues in Sect. 6 and moral issues in Sect. 7. We finally discuss some regulatory issues in Sect. 8, before concluding.

\section{The Context: Can Cultured Meat be a Solution?}

Cultured meat is emerging in a context in which the health, environmental and moral externalities of conventional meat production are increasingly documented; see, for example, Bonnet et al. (2020), Godfray et al. (2018), INRA (2017), IPBES (2019), IPCC (2019), Searchinger et al. (2018) and Springmann et al. (2016). While smallholder animal husbandry is important for subsistence in some poor countries, the case against animal agriculture is substantial in rich countries. As the COVID-19 crisis reminds us, animal food is at the origin of most emerging infectious diseases, either directly through zoonotic transmission from wild and domestic animals, or indirectly through agricultural expansion and intensification that favors the exposure of humans and their livestock to wild animals (Jones et al. 2008; Rohr et al. 2019; Espinosa et al. 2020).

Animal food production is also an incubator for antimicrobial resistance, given that about $70-80 \%$ of antibiotics worldwide are used for farm animals (Laxminarayan et al. 2013; O'Neill 2015). Additionally, animal food consumption raises a set of health issues. While meat contains some important nutrients, such as B12 vitamin, the overconsumption of red and processed meat, and of other animal products, has been associated with various adverse health outcomes, such as coronary heart disease, type 2 diabetes, obesity, calcium homeostatis, and numerous cancers (Bouvard et al. 2015; Vergnaud et al. 2010; Willett et al. 2019; Wolk 2017). ${ }^{4}$ It has been recently estimated that an individual should consume no more than $100 \mathrm{~g}$ of red meat and no more than $200 \mathrm{~g}$ of poultry per week (Willett et al. 2019). A high proportion of people in developed countries are currently consuming significantly more than this.

Poore and Nemecek (2018) provide perhaps the most comprehensive study to date on the environmental impacts of dietary choices. Using a life cycle analysis approach, they derive data from a large meta-analysis, covering 38,600 farms and hundreds of food operators. They compute the environmental impacts of about 40 food products over five dimensions: greenhouse gas (GHG) emissions, land and water use, acidification, and eutrophication. They indicate that animal products in the form of meat, aquaculture, eggs, and dairy use about $83 \%$ of the world's farmland and contribute about $57 \%$ of foods' different emissions, while providing only $37 \%$ of our protein and $18 \%$ of our calories. Although the impact of producing animal products may highly vary, depending on the method of production, they strikingly demonstrate that the "impacts of the lowest-impact animal products typically exceed those of vegetable substitutes" (Poore and Nemecek 2018, p. 987).

Meat production also involves important moral concerns due to the treatment of farm animals. It is estimated that more than 70 billion of terrestrial farm animals are raised and killed for food every year. These animals are usually slaughtered very young, after

\footnotetext{
4 Although these results correspond to "best science" in nutrition, based on hundreds of studies, we mention two limitations here. First, the great majority of studies are observational, and not causal. Second, meat over-consumption does not appear to be the main direct dietary risk factor (the main factors being a high intake of sodium and a low intake of whole grains, fruits, nuts and vegetables; see, for example, Afshin et al. 2019).
} 
about 6 to 8 weeks for broilers, and about 6 months for pigs. In developed country, a large majority of animals are raised in intensive farming conditions, namely in cages or in confined environments without outdoor access. This is the case for about $99 \%$ of farm animals in the US, where pigs for instance are confined for weeks in small crates, prohibiting basic movements including walking and turning around (Norwood and Lusk 2011). In parallel, animal sciences increasingly recognize the emotional and cognitive abilities of animals, including those of farm animals (Broom 2014; Marino 2017). These moral concerns are commonly advanced as a primary individual reason to reduce or ban the consumption of meat (Ruby 2012). These concerns also become more prominent politically, as illustrated by the frequent protests against food retailers and referenda about animal welfare.

There are essentially three (non-mutually exclusive) strategies to address these externalities. A first strategy is to target the supply side, namely food producers. The difficulty is that this strategy has been tried for decades, with very limited success. In Europe, for instance, it is recognized that the greening of the Common Agricultural Policy (CAP) has been globally a failure (Pe'er et al. 2014). For instance, there is still a positive correlation between CAP subsidies and pollution at the level of farms (Kirsch et al. 2017). Hence, the CAP still acts against the polluter-pay principle. Moreover, regarding animal welfare regulation, the improvement in animal rearing conditions is, at best, extremely slow. As an example, in the EU, which is one of the most advanced region worldwide in terms of animal welfare standards, many painful practices remain widespread within the industry, such as castration without anesthesia, dehorning, tail docking, teeth clipping, beak trimming, and slaughter without stunning.

The reasons for the failure of supply side strategies are multiple. First, it is difficult and very costly to monitor agricultural producers' actions. For instance, controlling water pollution is notoriously complicated because of the multiple and diffuse sources of pollution, and monitoring animal welfare in every farm is a daunting task. More generally, farms are numerous and scattered, making regulation difficult. Second, the agricultural sector is facing harsh international competition. This makes the implementation of stringent domestic regulatory measures more challenging, possibly inducing local economic costs and global pollution leakage. Third, there is a strong political capture by the agricultural sector, which implies under-regulation of (animal) agriculture in general (Howard 2017; Tschofen et al. 2019; Bonnet et al. 2020). Finally, and perhaps most importantly, it seems relatively ineffective to regulate food producers relative to consumers: Switching (even partially) to plant-based food is expected to have a much wider impact than improving agricultural practices for a given animal food, such as beef or lamb, for instance. Indeed, Poore and Nemecek (2018) conclude that "dietary change can deliver environmental benefits on a scale not achievable by producers" (Poore and Nemecek 2018, p. 991).

A second strategy is thus to address the demand side, namely, to directly target consumers. However, these strategies have also worked imperfectly. Again, there is evidence of under-regulation of meat consumption (Bonnet et al. 2020). Several reports or publications have emphasized that the retail food prices of meat do not reflect "true costs" (TAPPC 2020; Pieper et al. 2020), questioning, for instance, why meat products usually enjoy reduced VAT rates. The environmental regulation of meat products is also limited; for instance, no country has yet implemented a carbon tax on meat. Informational incentives also seem to work imperfectly. Labeling is an imperfect instrument in the context of a public good, such as the environment or animal welfare. Dietary guidelines mostly concern health issues (but increasingly include sustainability issues). In addition, although these guidelines are often used by public food services when planning meals, they probably have 
limited impact on consumers at large, and their recommendations have been shown to be insufficient (Springmann et al. 2020).

Moreover, there are strong behavioral limitations to dietary changes. It is indeed difficult to change ingrained food habits. People often lack the cooking skills and social support for dietary change, and perceive meat eating as "normal", "natural" and "necessary" (Piazza et al. 2015). Most people are strongly attached to meat (Graça et al. 2015). Fundamentally, the attraction to meat is evolutionarily "hard-wired", since it has a higher nutritional value than most crops, vegetables or fruits. This explains why eating meat usually provides more satisfaction compared to plant-based food (Zabraska 2016; Tuomisto 2018). Meat is in our biology but also in our culture, and pro-meat beliefs are permanently reinforced by existing social norms, values and policy (in)actions (Nyborg et al. 2016).

Additionally, it is important to reflect on global future trends. Even if meat consumption is slowing down in developed countries, it is strongly increasing in the developing world, especially in China and East Asia. Meat consumption usually increases with income (Godfray et al. 2018). While there is evidence of a slow decrease after a certain level of income is reached (Bonnet et al. 2020), the developing world is still far from this critical level. In a world with an overall growing and wealthier population, the demand for meat is thus expected to increase considerably. A review by the Food and Agriculture Organization (FAO) based on expert judgement projects an increase of $76 \%$ in the total quantity of meat consumed by 2050 (Godfray et al. 2018).

This increasing trend of meat production and consumption in developing countries is a serious problem for the environment, global health and food security into the future. Given that the satisfaction of meat consumers may induce strong political pressure, it seems unlikely that regulators in poor countries have the societal license to implement an aggressive supply- and/or demand-side policy to curb this trend, at any time in the near future. In particular, it seems unlikely that these countries would essentially go back in time and promote "less but better" meat produced through agro-ecological and smallholder farming methods, given increasing domestic demand. Consequently, we conclude that it may be necessary to resort to other solutions beyond the standard regulation of production and/or consumption of conventional meat.

Finally, a third strategy is the development of meat analogues and innovations. Indeed, there already exists a wide set of protein alternatives. Consider, for instance, processed plant-based protein, such as tofu, seitan, mycoprotein, or fungus (World Economic Forum 2019), as well as high-tech, plant-based options, such plant-based burgers (Rubio et al. 2020). All of these alternatives are promising and their associated production and market share have recently increased. Additional options include algae and insects. The rest of this paper focuses on one specific food innovation arising from cellular agriculture, ${ }^{5}$ namely, cultured meat. This innovation is in the early stage of its commercialization, however several commentators expect that various cultured meat products should reach the retail markets within a decade. The major perceived advantage of this innovation compared to the others is that it is intended to be molecularly extremely close to meat, and thus may become an almost perfect substitute to meat in terms of organoleptic properties (taste, texture etc.).

\footnotetext{
${ }^{5}$ Milk or egg analogues can be produced through the culture of micro-organisms, such as bacteria or yeast, which can generate proteins through fermentation. This technique is not novel, as it has been developed for several decades for products such as chymosin, used for cheese production, or amylase, used for beer and bread production.
} 


\section{Cultured Meat: A Brief History}

In this section, we first review the history of cultured meat (see Dillard-Wright 2013; Reese 2018 for more details), and then we attempt to summarize the latest technical advances and current challenges. As stated previously, the idea of cultured meat has long been around, but without the technique to achieve it. Cultured meat was apparently first mentioned in 1897 in a science fiction novel, entitled Auf Zwei Planeten, and appeared in a number of other novels in the last century, such as Ashes, Ashes (by René Barjavel 1943). In 1931, Winston Churchill (possibly inspired by friend, Frederick Edwin Smith), famously predicted: "We shall escape the absurdity of growing a whole chicken in order to eat the breast or wing, by growing these parts separately under a suitable medium. Synthetic food will, of course, also be used in the future." (Ford 2013, p. 44).

In vitro techniques (e.g., growing tissues for the treatment of wounds and diseases) have long been a standard part of laboratory-based science. In 1907, the biologist Ross Harrison cultivated frog nerve cells in a lymph medium at Johns Hopkins University. However, not much occurred regarding the development of cultured meat until the end of the twentieth century. In the late 1990s, Willem van Eelen filed the first patent on a culture meat production method. In 1998, the National Aeronautics and Space Administration (NASA) grew goldfish meat in the laboratory as a part of some research to produce food for prolonged journeys through space. It appears that the first cultured meat consumed by humans was through the work of the bio-artist, Oron Catts. In his 2003 project, Disembodied Cuisine, he managed to culture cells from a frog and presented them as tiny frog steaks during a dinner at a museum in Nantes, France (Catts and Zurr 2007). ${ }^{6}$

In 2005, the Dutch government funded two research projects on cultured meat (Stephens et al. 2018), and the medical researcher, Mark Post, and Google's cofounder, Sergei Brin, partnered to accelerate its development. The first scientific publication on cultured meat occurred in 2008, and the number of publications since 2013 has increased considerably (Chriki and Hocquette 2020). In 2008, the Food Research Institute of Norway organized a conference on cultured meat. Public visibility increased widely after a television show in 2013 in London where Post cooked cultured meat and two journalists publicly tasted it, declaring that "it was close to meat". The first commercialization of a cultured meat product occurred in December 2020 in a restaurant in Singapore.

Two nonprofit organizations, New Harvest, and later, the Good Food Institute, have been key players in supporting the research and development (R\&D) of cultured meat. Much of the advanced work in the field has been (and continues to be) conducted within startups. Nowadays, there exist about 50 startups around cultured meat and seafood (Cameron and O'Neill 2019; Rubio et al. 2020). ${ }^{7}$ Most startups are currently located in the US and the EU, with few additional ones located in Israel and in Asia (Rubio et al. 2020). Most investors are private ones; and include billionaires (such as, Li Ka-shing, Bill Gates and Richard Branson), but also the conventional meat sector, with large companies in the US (Cargill or Tyson Foods) or in the EU (PHW, Migros or Grimaud). The amounts invested

\footnotetext{
6 The frog that was used as the cell donor was present at the performance dinner, possibly illustrating the fact that one can eat meat without killing.

7 They focus on beef (e.g., Aleph Farms, Meatable, Memphis Meat, Mosa Meat), pork (e.g., Higher Steaks, Memphis Meat, New Age Meats), chicken (e.g., Cubiq Food, Eat Just, Super Meat, Vital Meat), foie gras (e.g., Gourmey, Integriculture, Peace of Meat), fish (e.g., BlueNalu, Finless Foods, Wild Type), and pet food (e.g., Wild Earth).
} 
have increased drastically over the last years, but remain modest compared to investments in plant-based food companies (Cameron and O’Neill 2019).

As discussed, the basic technique used to produce cultured meat builds on tissue engineering, and is not really novel. This technique has largely focused on medical applications, such as regenerative medicine, and non-animal in vitro models used in toxicology and drug development. The production of cultured meat is yet to be scaled up to an industrial level, and it is difficult to know with precision what startups are exactly focusing on. However, the general principles are known. A tentative summary is presented in Fig. 1 (Tuomisto 2018). In short, stem cells are taken from muscle tissue or embryos and are first expanded and then differentiated into muscle cells. These cells are further put into a bioreactor where they multiply, and are transferred to a matrix or scaffold to grow into muscle fibers and larger tissue. The growth medium appears to be the critical aspect, in terms of cost and uncertainties (Specht 2020; Post et al. 2020). ${ }^{8}$

The R\&D of cultured meat still faces a number of technical challenges. Most likely, burgers and nuggets should be produced long before steak. Indeed, growing a complete muscle tissue with its network of membranes and filaments requires a complex system with multiple cell types growing in an organized manner, and a structure with a replicated blood vessel network (Stephens et al. 2018). Obtaining the marbling of meat may also be very challenging. Moreover, it is not yet clear how to reproduce in vitro the natural color or the tenderization of meat due to the natural maturation process (Hocquette 2016). For a minced product, the scaling is also different than for a full-thickness meat product, especially for the final stage of the organoid or tissue production (Post et al. 2020).

Hence, cultured meat techniques are potentially some way from being able to reproduce the diversity and texture of various meat products (Ford 2013; Chriki and Hocquette 2020). Moreover, it is not clear which cell types or growth medium future producers will use. Yet, it seems almost certain that the technique will not rely on animal-derived products, such as the foetal bovine serum used in the early stages in the growth medium (Specht 2020) or the bovine collagen used in the scaffold (Young and Skrivergaard 2020). In any case, significant technical improvements are still needed for the process of cultured meat production to be cost-efficient and to be brought to production at scale for food supply, from cell selection and medium optimization to biomaterials, and tissue engineering (Post et al. 2020).

\section{Some Demand Side Issues}

In this section, we explore the impact of cultured meat on consumers. As a preliminary remark, we recall that expanding consumers' set choice is usually considered to be good for consumers' welfare. Some consumers may simply ignore the new product, while others may readily consume it. This is the standard decision theory benchmark, where it is assumed, for instance, that the additional flexibility does not generate (e.g.) confusion or regret, which may arise because of imperfect information or behavioral dimensions (Iyengar and Lepper 2000). Hence, at a basic level, the availability of cultured meat is expected

\footnotetext{
${ }^{8}$ We should add here that Fig. 1 only represents one potential model for cultured meat production, but there are also other options (e.g., other types of bioreactors could be used, scaffolds may be used already at the proliferation phase too, or scaffolds may not be used at all). Furthermore, Hopkins and Dacey (2008) and Gaydhane et al. (2018) also mention the use of different techniques to produce meat in the laboratory, such as organ printing, bio-photonics or nanotechnologies.
} 


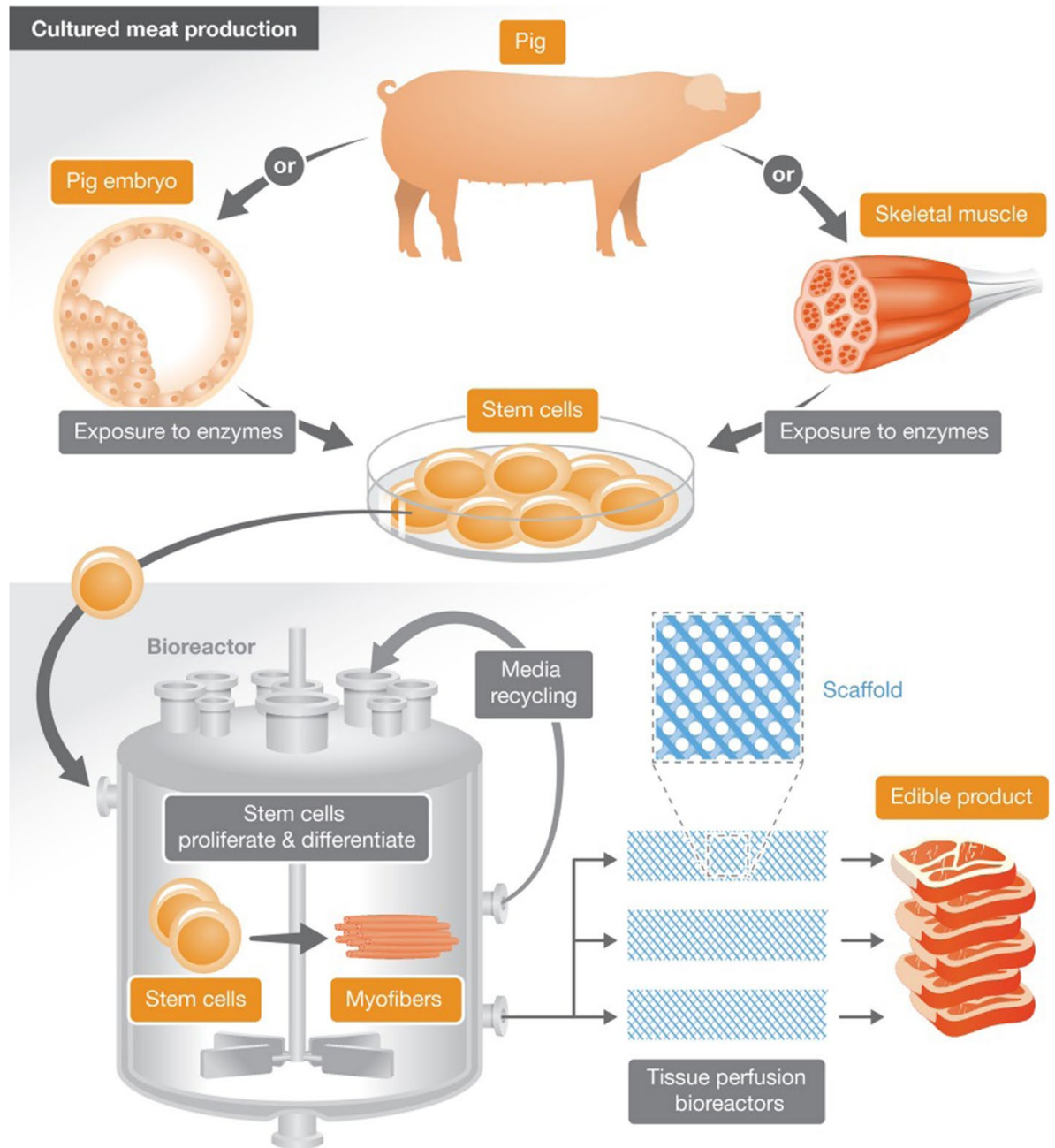

Fig. 1 The production process of cultured meat. Source: Tuomisto (2018). This figure represents the three main stages of the production of cultured meat. First, stem cells are taken from muscle tissue or embryos and are expanded and then differentiated into muscle cells. Second, these cells are further grown in a bioreactor to increase their number. Third, the cells are then transferred to a scaffold to grow these into muscle fibres and larger tissue. (Figure reproduced under the Creative Commons Attribution 4.0 Unported Licence (CC BY), https://creativecommons.org/licenses/by/4.0/)

to increase consumers' welfare. ${ }^{9}$ Note that it may also allow vegetarians to consume 'meat' again.

We re-emphasize here that conventional meat and cultured meat differ drastically in their production methods, but that they may, or may not, also differ in taste and properties.

\footnotetext{
9 Note however that stimulating meat consumption may raise health issues, and thus decrease welfare, as argued in Sect. 2. On the other hand, cultured meat could be healthier than conventionally produced meat as the type of fat can be chosen, so that it is possible to use healthy fats.
} 
On the negative side, the technique may never be able to perfectly reproduce the exact conventional meat options that consumers want, as suggested above. On the positive side, however, due to advances in available technology, variant versions of meat may be produced, such as "profiled meat" (e.g., meat adjusted in terms of healthier content and type of fat, or in terms of B12 vitamin), that may be preferred to conventional meat by (some) consumers. This latter argument is a standard one made by the agro-food sector regarding processed food that has been used for vitamins, micro-nutrients, etc. Again, this additional choice flexibility should increase consumers' welfare.

There is currently no market for cultured meat; hence, its demand cannot be precisely assessed, but only forecasted. Until now, the literature on the demand side has mostly consisted of studies on consumers' acceptance, by means of either experimental, survey or focus group studies. Stephen et al. (2018) emphasize the diversity of responses within and across studies. Here, we mostly rely on the meta-analyses conducted by Bryant and Barnett $(2018,2020)$. They report that the proportion of participants willing to try cultured meat varies significantly, from 5 to $11 \%$ in Hocquette et al. (2015) and up to $65 \%$ in Wilks and Philips (2017). ${ }^{10}$ Those who are more willing to accept the innovation are, on average, more educated, younger and more liberal. A major factor affecting acceptance levels is the presence of aesthetic concerns around the taste, texture and appearance of cultured meat. Participants also suggest various other concerns, including 'unnaturalness', 'disgust', 'safety', 'healthiness', and anticipated price.

Some studies examine the specific factors that particularly influence consumers' acceptance. In a recent study, Weinrich et al. (2020) find that ethics is the stronger driver. Interestingly, informing participants about the technical details of cultured meat production may not increase acceptance (Siegrist et al. 2018). An important factor that reduces acceptance is the "naturalistic heuristic"; that is, the belief that "what is natural is good". MacDonald and Vivalt (2018) study the impact of debunking messages on this heuristic, finding that the most efficient message is to "embrace unnaturalness" rather than to deny it. They also indicate that the impact of anti-cultured meat messages seem to be particularly resilient, thus suggesting that campaigns against the innovation may be effective in decreasing acceptance. Along this line, Bryant et al. (2019a, b) find that arguing that conventional meat is unnatural resulted in a significant increase in some measures of acceptance of cultured meat compared to other messages.

It is also interesting to observe that several participants in the studies seem to display an initial reaction of disgust. As emphasized by Hopkins and Dacey (2008), disgust is often largely cultural. It could be due, for instance, to some perceived immorality of the innovation. However, we will argue later that this moral argument does not rest on solid ground (Hopkins and Dacey 2008), and thus may likely be diminished over time. Disgust can also simply be due to a form of neophobia, so that people may not continue to feel it when they are educated about, and more familiarized with, cultured meat and how it is produced. However, Bryant and Barnet (2018) report that there is also evidence of broader societal concerns about the end of conventional animal agriculture, distrust of companies producing cultured meat, and the energy required for production.

\footnotetext{
10 A recent unpublished meta-analysis is available on the Animal Charity Evaluators website (accessed 22 March 2020): https://animalcharityevaluators.org/research/other-topics/a-systematic-review-of-cell-cultu red-meat-acceptance/. This analysis emphasizes that there is a risk of publication bias because many studies were conducted and funded by animal advocacy organizations or other groups invested in cultured meat.
} 
Wilks and Philips (2017), Slade (2018) and Tucker (2014) report that males are, on average, more willing to try cultured meat. This gender effect may be surprising at first, since there is a lot of evidence that males have more positive attitudes toward conventional meat. Indeed, males consume more meat in general, and participate less in meatless day initiatives, for instance (Bègue and Treich 2019). Moreover, meat is associated with perceived masculinity and domination (Ruby and Heine 2011; Rothgerber 2013). A possible explanation may be that males are generally more willing to accept innovations, as was the case for GMO products (Moerbeek and Casimir 2005). Another explanation may be that females are generally more concerned by possible health issues associated with new food products, especially because females are most often responsible for the purchase of foodrelated products on behalf of the whole family. They might also be more sensitive to scientific uncertainty and more willing to adopt vegetarian food as an alternative to conventional meat.

One limitation of the existing consumers' acceptance studies is that they do not usually examine price effects, such as consumers' WTP or demand at several price-points. As an exception, Van Loo et al. (2020) surveyed more than 1800 US consumers who completed a choice experiment. In each choice, consumers had five options: conventional farm-raised beef, a plant-based burger made with pea protein, a plant-based burger using animal-like protein produced by yeast, cultured meat, or they could choose not to buy any of the products. Van Loo and coauthors show that holding prices constant and conditional on choosing a food product, $72 \%$ of survey participants chose farm raised beef and only $5 \%$ chose cultured meat. Even at significant discounts, most participants preferred conventional beef. Adding brand names (Certified Angus Beef, Beyond Meat, Impossible Foods, and Memphis Meats) actually increased the share of participants choosing farm raised beef to $80 \%$. However, vegetarians, males and younger and more highly educated individuals tend to have relatively stronger preferences for cultured meat relative to farm-raised beef. Two other recent WTP-based papers (Asioli et al. 2020; Carlsson et al. 2021) also find that consumers largely reject cultured meat, and other similar results.

It is important to emphasize some methodological limitations of existing consumers' acceptance studies. Most importantly, these studies are hypothetical, and thus by their very nature face traditional issues regarding hypothetical bias in survey studies. Interestingly, Rolland et al. (2020) remove one central hypothetical dimension by informing consumers that they could taste real cultured meat while they were, in reality, eating conventional meat. In other words, they used deception in their tasting context. Interestingly, they found that all participants tasted the "cultured" hamburger and evaluated its taste to be generally better than the conventional product, in spite of the absence of an objective difference. Moreover, they found that a previous awareness of cultured meat is the best predictor of its acceptance, emphasizing the importance of familiarity. This raises another, and quite unavoidable, limitation of consumers' acceptance studies, namely that the context is very unfamiliar. Survey participants had never been exposed to the food product, and some may never have heard about it.

As a result of the hypothetical bias and unfamiliarity, consumers' acceptance studies may not be very reliable. Unsurprisingly, results are highly variable across studies, and display a high sensitivity to wording and framing (Asioli et al. 2020; Bryant and Dillard 2019). More fundamentally, it is extremely difficult to anticipate future beliefs towards this innovation, as well as the future social norms and political context, when cultured meat is in fact commercialized. It does not seem unrealistic, for instance, that omnivores will face increasing social pressure in the coming decade to reduce or avoid meat eating when animal friendly alternatives become available. The possibility of consuming cultured meat 
or other protein alternatives may in turn increase the salience of the issue, for instance in restaurants, if the alternatives are systematically offered on menus, and contribute to progressively changing social norms in return.

Interestingly, Bryant et al. (2019a, b) find that meat attachment predicts cultured meat acceptance, but not plant-based meat acceptance. This indicates that cultured meat could be more able to displace demand from heavy meat-eaters who do not want plant-based alternatives. A related open question concerns the future attitude of vegetarians (or vegans). Vegetarians currently represent between 3 and $10 \%$ of the population in developed countries. These figures appear to be increasing, especially in the young segment of the population (The Economist 2018). What will vegetarians do when cultured meat options become widely available? Most vegetarians may simply not care, and stick to their current eating habits. However, this may depend on the reason why people became vegetarians in the first place (Ruby 2011). Some may be attracted by the possibility of eating meat without hurting animals, while others-perhaps those motivated by health or ecological reasons-may be concerned by health impact uncertainties, or the energy-intensive and technical aspects of its production, and may reject cultured meat on these grounds.

This discussion about the demand of some segment of consumers and food substitution effects raises an important question about the economics of (cultured) meat. One can speculate and imagine various scenarios that might shape future meat markets. One scenario corresponds to a situation where cultured meat companies manage to produce cost-efficient products, typically for minced meat analogs. These products may attract heavy consumers of (low-quality) meat products, typically the products coming from industrial animal farming. Note that these products may also obtain significant market shares in developing countries. This scenario may thus have wide consequences for the meat production sector, as well as wide health, environmental and moral consequences. Another scenario is that of a "niche" market. If cultured meat products remain (much) more expensive than conventional products, they may only attract specific consumers, such as flexitarians or vegetarians and/or those more sensitive to the externalities of their consumption and not much concerned by the highly technical mode of production. Likewise, these products may only be reserved to special occasions or specific dishes, such as cultured foie gras. The implications of this scenario for the society at large may be small.

Many other complex or subtle questions arise. Sebo (2018) discusses, for instance, the question of identity. He argues that many people see their gender identity, sexual orientation, cultural identity, religious identity, national identity, professional identity, and so on, as strongly connected to meat consumption. If this hypothesis is correct, and there is evidence for it (e.g., Atkin et al. 2018), people will have to ask themselves: Are their practices and traditions compatible with cultured meat? And, if not, how could this conflict be resolved? Sebo further emphasizes that when disruptions occur, people tend to react defensively, in an attempt to preserve familiar ways of thinking, feeling and behaving.

A related implication concerns the meat paradox hypothesis: consumers form self-serving beliefs in order to reduce the feeling of guilt associated with meat eating (Loughnan et al. 2010; Hestermann et al. 2020). That is, people like to eat animals but do not like to feel responsible for the suffering and slaughter of animals, and look (perhaps subconsciously) for excuses and justifications. Interestingly, the standard models of cognitive dissonance would then predict that the simple availability of meat alternatives, such as cultured meat, may increase ethical beliefs towards the environment and animals. Vivalt and MacDonald (2018) tend to reject this hypothesis, unless the "naturalistic heuristic" is properly controlled for. That is, they show that those who perceive cultured meat positively do indeed change their ethical beliefs, consistent with cognitive dissonance theory. 
This hypothesis reminds us of the complexity and diversity of psycho-sociological attitudes towards meat. Research in anthropology by Vialles (1988) distinguishes the "zoophages" (i.e., people who like to recognize that they consume animals) from "sarcophages" (i.e., those who prefer to consume an abstract product unrelated to animals). A priori, cultured meat may provide satisfaction to the latter category but not to the former, unless, as discussed in Burgat (2019), there is an efficient symbolic substitution. ${ }^{11}$ Burgat concludes that cultured meat raises the question of what meat really is, and that it is not unthinkable that a meat-based diet will continue to exist in people's minds even after conventional meat has been replaced by cultured meat. Relatedly, Van der Weele and Driessen (2019) conclude that when it is no longer clear what meat really is, the meanings and experiences of eating it become unsettled. Within this process, the ambiguity and ambivalence of conventional as well as cultured meat are of central interest. This process provides additional reasons for the limitations of studies predicting future consumers' choices.

\section{Some Supply Side Issues}

In this section, we explore some issues related to the supply-side impacts of cultured meat. As we discussed in the previous section, the availability of cultured meat should generate substitution effects. That is, if cultured meat is successfully developed, the producers of meat may likely differ from current ones. This may typically induce a costly transition for the workers in the conventional animal farming sector, including animal farmers, animal feed producers, vets, etc. There may also be regional effects, as the availability of some agricultural land may no longer be necessary to produce meat. An important issue is whether or not cultured meat production will continue to use traditional agricultural products (vegetables, legumes, sugar, etc.) in the provision of nutriments used in the growth medium. A related issue concerns the fertilization of these products, if cultured meat implies less animal farming and thus less manure. ${ }^{12}$

Cultured meat may also significantly affect market power. One common fear is that the world's protein production sector will become even more concentrated. Although this fear may sometimes be expressed colloquially as a hot-blooded critique of capitalism and outright rejection of technology, ${ }^{13}$ it should be taken seriously. Indeed, with the introduction of a new technology with high entry costs and constant or increasing returns to scale, there is a potential for a natural monopoly. If a firm is able to produce (and patent) the most competitive cultured meat product(s), it is likely that this firm could duplicate the production

\footnotetext{
11 More precisely, building on a structuralist hypothesis, Burgat argues that the act of eating meat reveals a desire for a murderous relationship of a particular type; a desire brought to light by the revulsion of cannibalism.

12 It seems unlikely a priori that our societies would face a shortage of animal manure unless there is a drastic reduction in animal farming. Moreover, we add that this is a misconception to say that reducing the number of livestock would reduce the amount of fertilisers. Livestock does not produce more nutrients; they just convert the feed to manure and the manure contains less nutrients than the feed (we thank a reviewer for this point). In addition, we highlight here the potential of mulching and microbial biofertilizers (Schütz et al. 2018; Wang et al. 2019).

13 The involvement of Silicon Valley venture capitalists and big philanthropists, as discussed before, as well as collaboration with powerful meat industry and fast food corporations, is typically perceived as a dangerous signal (Broad 2019). The sociologist Porcher (2019) even talks about a "collusion of interests" between animal advocacy NGOs and capitalism.
} 
essentially everywhere, and secure the whole market. We are in a winner-takes-all situation typical in an intangible economy: value is mostly based on ideas and knowledge rather than on physical capital (Haskel and Westlake 2018). An additional concern is that large multinational companies that are rich in intangible (and thus highly mobile) assets may more easily optimize their financial exposure. Moreover, an important related question concerns who is going to receive the value added by the innovation. If this innovation succeeds, it is likely that this will be to the profit of inventors and processors and at the expense of farmers, possibly aggravating an already unbalanced situation.

Importantly, this general fear of increasing market power should not be exaggerated. First, we must recall that the meat sector is already very concentrated (Howard 2017). In fact, corporate concentration is important through the entire industrial food system: seeds and agrochemicals, fertilizers, animal pharmaceuticals, livestock genetics, farm equipment, food processors and retailers (IPES-FOOD 2017). Second, we argue that it is likely that the introduction of the innovation will —in the coming decades - induce more, rather than less, competition in the sector. This is because conventional, plant-based and cultured meat will likely coexist for several decades, as some food experts predict (ATKearney 2019). Moreover, we must recall that there are various types of meat; and that it is not clear whether the same cultured meat producer can simultaneously obtain a key advantage on most types of meat, namely for very different ones, such as steak, pork, chicken, foie gras, fish, etc. Indeed, as we are clearly observing now, startups are specialized as to a specific meat type (see Sect. 3). Finally, we must recall the wide heterogeneity of tastes of consumers, both within and across countries. Hence, overall, it seems quite unlikely that only one (or a few) firms will dominate the world protein market, and it is not even clear that the possible emergence of cultured meat will eventually lead to more market concentration.

A central economic question concerns the cost of production of cultured meat. This cost is very difficult to predict because the production technique is not stabilized, startups' private costs are largely hidden and it is difficult to anticipate the effect of high scale production. There exist several back-of-the-envelope calculations in the literature that vary by a factor of 10 or more (Rubio et al. 2020). Specht (2020) has provided the most advanced analysis so far. She indicates that the growth medium - which is the most significant cost driver - can be produced completely free of animal derived components and at scales and price points several orders of magnitude lower than current costs, without relying on fundamentally new technologies. She then concludes that it is likely that cultured meat can achieve price parity with mainstream conventional meat once produced at an industrial scale. By contrast, Orzechowski (2015) believes that producing cultured meat at a competitive price may never be achievable. ${ }^{14}$

What about the impact of cultured meat on the supply chain? This impact is difficult to anticipate. Several commentators suggest that cultured meat might be produced in small factories, such as "urban breweries". This form of production will have several advantages. Typically, it is less sensitive to external (e.g., weather) conditions than conventional meat production. More rapid production time also induces more flexibility to adapt to demand (less time to produce, etc.), which is valuable in crisis periods and may also help address global food security issues. However, given the expertise required and the high investment costs of the innovation, it seems unlikely that cultured meat immediately benefits the poor in developing countries. We must reiterate here that animal agriculture is often essential for

\footnotetext{
${ }^{14}$ Given the possible difficulty to reach competitive prices in the near future, we note that it is not very surprising that several startups specialized in luxury and expensive products, such as foie gras.
} 
the subsistence for farmers in poor countries, and that it is less sensitive to weather compared to plant productions. Hence, cultured meat may not be the most pressing innovation in those countries. Nevertheless, this innovation may certainly help to nourish inhabitants in the growing cities in third world countries. For this, technology transfer programs may be required so that cultured meat could become an important source for food (Tuomisto 2018). Broad (2019) concludes that there is a path by which animal product alternatives could help promote "food tech justice." The existence of this path partly also depends on whether cultured meat mitigates or exacerbates the dependence on petro-chemical inputs and large-scale monocropping.

We now briefly discuss some R\&D issues. We first note that cultured meat is a typical case of process innovation, although it can also induce product innovation, as suggested in the previous section. For the moment, the major part of the effort and the funding comes from private investors, who are often wealthy billionaires, as mentioned before. This is not surprising. Cultured meat is a very risky and long-term venture, which requires a great deal of funding capacity. It also requires an appetite for technology. Moreover, it is well known that the traditional banking system is reluctant to finance risky innovations, since startups do not have tangible assets that can serve as collateral and they typically possess more information than the banks about the potential of their novel products. We add that aspects of philanthropy (especially related to animal welfare, see below) have also played an important role in the R\&D of cultured meat. Several philanthropic NGOs have indeed funded research projects on cultured meat. This can be critical since the relevant research has been in a kind of academic "no man's land", located at the interface of food production and medical research (Reese 2018).

This novel food product is particularly interesting regarding the recent economic literature on innovations. For instance, Akcigit and Kerr (2018) and Acemoglu et al. (2020) consider a growth model with heterogeneous innovative firms. That is, their model distinguishes between incremental and radical innovators. Incremental innovators are incumbents who invest in internal innovations to improve their existing products, while radical innovators are new entrants who invest in external innovations to acquire new product lines. In this model, although incremental innovations increase productivity, the radical innovations are the engine of growth. This is because incremental innovations in a particular technology cluster run into diminishing returns, while radical innovations create new technology clusters and generate another series of incremental innovations (Acemoglu et al. 2020). Hence, the research on cultured meat vs. that on conventional meat provides a nice example of the difference between both types of innovations, and an important domain of application to explore (e.g.) how funding and human capital are sorted across different innovators.

Furthermore, we raise political economy issues regarding the funding of research and the role of academia. It is well known that large incumbent industries, such as those existing in the meat sector, often bias research outcomes and shape the research agenda. In addition, large industries, such as pharmaceutical companies, are also harnessed to animal production (e.g., through the development of antimicrobial medicine), reinforcing the political power behind animal farming. Innovations are often prone to introducing new harms, ${ }^{15}$ most typically when efficiency gains in production come at the expense of animal welfare,

\footnotetext{
15 We provide an illustration. The wide-spread use of an anti-inflammatory drug (i.e., diclofenac) to treat livestock has led to a dramatic decline in the vulture population in India, eventually generating an epidemic of rabies (Markandya et al. 2008).
} 
global health, smallholders, or ecosystems. Thus, a vicious circle is generated: innovative academic research on animal farming is required to fix problems that were induced by previous industrial trends and supportive research, and so on, while the need would also be to change the system more globally and radically.

Finally, we discuss the impacts on employment. These impacts are not clear either. Currently, a few hundred people work full-time in cultured meat companies. Many more highskilled jobs in this knowledge economy are expected to be created in the near future. ${ }^{16}$ That is, the perspective of producing food differently, without exploiting animals, may create a myriad of economic opportunities that are difficult to anticipate today. Van der Weele and Tramper (2014) even stress opportunities for conventional animal farmers. Indeed, they report that a cultured meat scenario has generated great enthusiasm among their workshop participants: one in which pigs in backyards or on animal-friendly (urban) farms would serve as the living donors of muscle stem cells through biopsies. This scenario may mitigate worries of cultured meat being unnatural, and evoke positive reactions due to the maintenance of local production and links with domesticated animals. This observation emphasizes that the mode of production of cultured meat matters for consumers and from producers' viewpoints. Relatedly, it seems likely that the quality of the working environment would be increased under cultured meat production. The conventional meat industry has indeed a reputation for being dirty and dangerous, as well as a long history of exploiting immigrants and vulnerable workers (Broad 2019).

\section{Some Environmental Issues}

Cultured mead has often been called "clean meat". Some food experts indeed consider that cultured meat has the potential to drastically reduce environmental externalities (Gasteratos 2019). To date, there exist however only a few studies in the academic literature, which are mostly based on life cycle analysis. In an early and explorative study, Tuomisto and Teixeira de Mattos (2011) conclude that compared to conventional European meat, cultured meat involves 78-96\% lower GHG emissions, 99\% lower land use, and 82-96\% lower water use. These numbers are significant, but they rely on speculative assumptions about the production of cultured meat. In their study, the authors hypothesized a system in which animal embryonic stem cells are grown in a cylindrical stirred tank bioreactor, in a medium of cyanobacteria hydrolysate, vitamins and animal growth factors. ${ }^{17}$

Mattick et al. (2015) also use an anticipatory life cycle analysis to study the environmental impacts of cultured meat, and compare the results with published impacts of beef, pork, poultry (see Fig. 2). They also find that cultured meat requires smaller quantities of agricultural inputs and land than livestock. However, they emphasize that these benefits could come at the expense of more intensive energy use. Indeed, their study showed three times

\footnotetext{
16 Recall, for instance Henry Ford's innovations, which rendered horse-drawn carriage coachmen unemployed. As is well known, the development of automobile created a new economic sector with many more jobs.

17 A few years later, Tuomisto et al. (2014) amended the previous study by considering an alternative growth medium based on plants (wheat and maize) and an alternative (hollow fiber) bioreactor as well as some differences in the life cycle assessment method. They found similar results as in Tuomisto and Teixeira de Mattos, with the notable exception of an important increase in energy and water use. More recently, Alexander et al. (2017) indicate that the impact on land use is very sensitive to the growth medium (e.g., algae vs. animal feed), and suggest that the land use reduction may have been overestimated.
} 
higher energy use compared to previous studies, which was explained by the steam cleaning, different composition of growth medium and different bioreactor design (Tuomisto 2018). Smetana et al. (2015) examine a wider spectrum of environmental dimensions and find that cultured meat may generate more externalities compared to several meat alternatives, such as gluten-, soymeal- or insect-based substitutes. Post et al. (2020) stress that some components need to be present in high concentrations for producing cultured meat, such as glucose and amino acids, and that these components have a strong impact on the environmental footprint of the process.

Rubio et al. (2020) emphasize the potential for technological progress; indeed, the production of cultured meat is expected to, once optimized, require much fewer resources. Anticipated reductions include in particular targeted tissue cultivation, higher production rates, growth medium recycling and vertical production systems. Similarly, Post et al. (2020) emphasize that alternative sources of amino acids and peptides, such as biomass from algae, could provide cheap sources of enriched amino acids, fats, vitamins and minerals, and in turn offer opportunities for more sustainable processes. The overall environmental benefits of cultured meat production also heavily depend on how the released land from livestock production would be used, and hence on assumptions regarding carbon storage opportunity costs (Searchinger et al. 2018). Additional benefits may occur: cultured meat might also reduce transportation and refrigeration costs, and possibly also waste products, because it is expected that cultured meat should have a longer shelf life than conventional meat (Gasteratos 2019). Note also that cultured meat production does not raise issues of carcass waste management.

Using previously mentioned life cycle assessment studies as sources of data, Lynch and Pierrehumbert (2019) compare the GHG emissions of cultured meat production to three different beef production systems. Although they show that cultured meat usually generates much less pollution than beef, they conclude that in one scenario cultured meat is not always more climate-friendly. This is because cultured meat emissions are made almost entirely of $\mathrm{CO}_{2}$ from energy generation, and because $\mathrm{CO}_{2}$ remains longer in the atmosphere than methane or nitrous oxide emitted by conventional meat production. Hence, they find that in the long term, cultured meat may even generate more climate damage than beef. However, this conclusion is very tentative since the result occurs only after hundreds of years in the simulations. Moreover, Lynch and Pierrehumbert assume no decrease in the emissions associated with energy production. The potential for energy transition reducing pollution over such a long period of time thus make these calculations highly speculative, and also highly biased against cultured meat. Finally, and perhaps most importantly, these estimates do not capture carbon opportunity costs due to land use which can severely increase the conventional meat footprint (Searchinger et al. 2018). Indeed, these carbon opportunity costs reduction (and possible other benefits such as those on biodiversity) associated with the large expected reduction in land use induced by cultured meat (see Fig. 2) is probably the major environmental benefit at this stage (Hayek et al. 2020).

Lynch and Pierrehumbert's study further illustrates the lack of reliability of existing prospective academic literature on cultured meat. The technology is still in its infancy, and future emissions will depend on exactly how production is completed and scaled, as well as on the opportunities to reduce emissions from other parts of the life cycle. It also emphasizes the need to combine the impact analysis with more coherent scenarios regarding the supply of clean energy in the future. Moreover, the energy inputs from cultured meat are typically more flexible and substitutable than those of conventional meat. For example, the choice of a cultured meat production site should be less dependent on environmental (e.g., geography, weather) conditions, and may be more closely positioned to the demand, or 


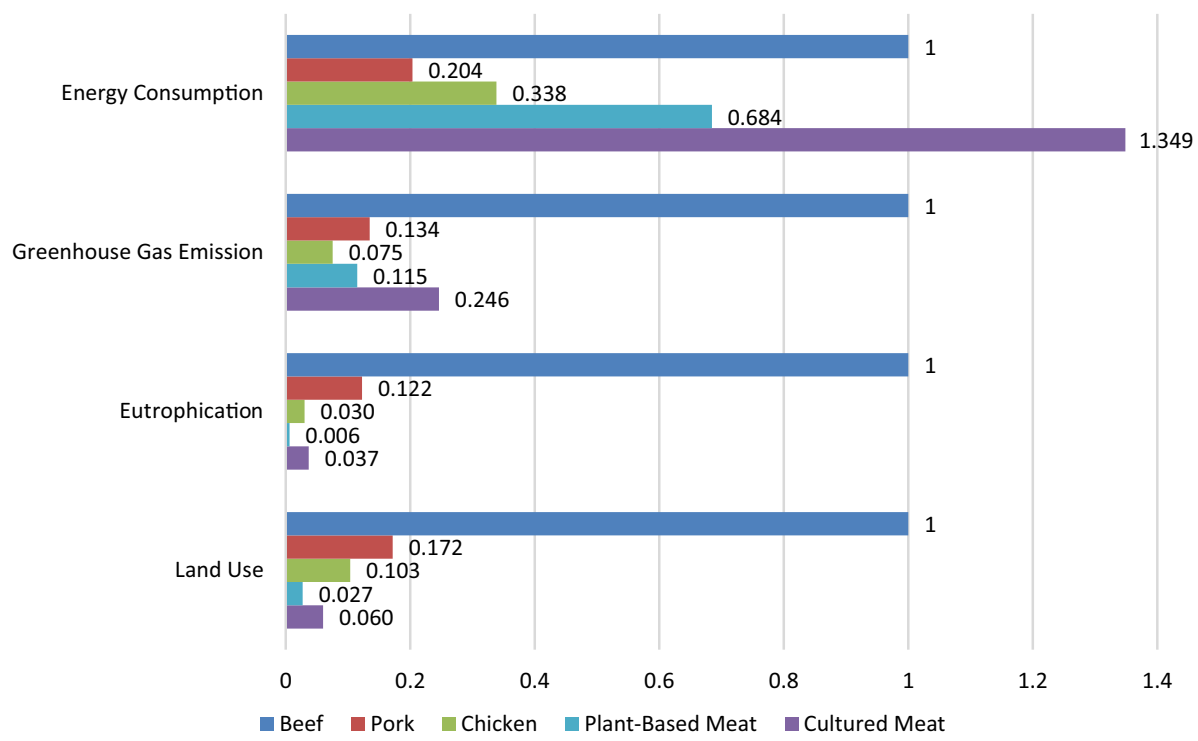

Fig. 2 Comparison of environmental impacts of cultured meat with other meat products. Source: Rubio et al. (2020). Data are normalized to the impact of beef production. This Figure is slightly adapted from Fig. 5 in Rubio et al. (2020), which uses data from Mattick et al. (2015) and from life-cycle analyses of specific plant-based meat products. (Figure reproduced under the Creative Commons Attribution 4.0 International Licence, https://creativecommons.org/licenses/by/4.0/)

more easily powered with solar panels by choosing sunny locations. This should reduce the environmental impact of global supply chains, such as shipping and trucking. In other words, there are opportunities to optimize the production of cultured meat in ways that reduce GHG emissions (World Economic Forum 2019).

This discussion about the environmental impacts of cultured meat emphasizes that (environmental) economists can efficiently contribute to the research on the topic. First of all, economists can combine the existing research based on a life-cycle analysis with a benefit-cost analysis. Life-cycle analysis typically does not compare different decisions, and does not account for global, sequential, and strategic effects. If a significant share of the future meat market includes cultured meat, large changes in land usage and crop production are expected, thus affecting prices, with further impacts on economic incentives and so on. Moreover, as explained above, some environmental benefits depend on the transition to clean energy sources. Overall, a full-fledged analysis of the various trade-offs requires an integrated approach properly connecting agricultural, food, land use, environmental and energy issues. Additionally, uncertainty (and thus learning) is prevalent, and economists master tools for decision-making under uncertainty, such as option value theory. Hopefully, an emerging body of economic research should be able to provide insights and useful policy recommendations in some years on this topic.

As mentioned above, the large-scale production of cultured meat may have a significant impact on land use and thus on rural management; however, we are not aware of a thorough study on this aspect at is time. We make only a few comments here. First, we observe that cultured meat should be free from several limiting factors, such as the availability of pastures, land for animal feed, weather conditions, growing seasons, etc. This may be viewed as a benefit due to more flexibility and resilience, but also as a cost in terms of amenity 
value, depending on how people view conventional agricultural amenities compared to the alternative (e.g., forests). Previous research has studied the impact of conventional agriculture on the quality of the environment or the landscape (e.g. Desjeux et al. 2015). While pastures may generate positive environmental externalities and amenities, it is certainly not the case for animal production facilities for instance (Ready and Abdalla 2005). Moreover, living near these facilities may increase morbidity and mortality risks, for instance through exposure to air pollution (Sneeringer 2009). As previously mentioned, cultured meat could be produced in countries with little or no agricultural land. From this viewpoint, this is not a surprise that Singapore is the first country to commercialize cultured meat. Changes in the location of local and global production of meat should in turn profoundly reshape the economic and social networks in such a way that it remains difficult to make predictions today, since the location of production of cultured meat and the exact inputs required are not known.

We briefly conclude this section by discussing some (environmental) health issues. As is well known, standard meat production causes local contamination of water, soil and air. A recent study indicates, for instance, that the main air polluting sector in the US today is agriculture, due mainly to animal farming (Tschofen et al. 2019). As previously discussed, the large majority of infectious diseases originate in animals. Swine and avian flu repeatedly occur in the farming industry (Espinosa et al. 2020). A large portion of food-borne pathogens such as Salmonella, Campylobacter and Escherichia coli come from animal food. Fecal contamination is also widespread in slaughterhouses (Gasteratos 2019). These specific problems are all ultimately due to humans' manipulation, confinement and killing of living animals. They thus should largely disappear with the production of cultured meat.

\section{Some Moral Issues}

In this section, we discuss moral issues related to animal welfare. Cultured meat is often presented as a form of cruelty-free agriculture, since no animals are slaughtered to obtain meat. Many animal advocates and philosophers consider that encouraging the development of the innovation is therefore a moral obligation (Hopkins and Dacey 2008). Several animal protection NGOs support cultured meat. As an example, in 2008, People for the Ethical Treatment of Animals (PETA) offered a one million dollar reward to the first research lab to produce a commercially viable cultured chicken nugget. As mentioned earlier, some philanthropic organizations have also funded R\&D on cultured meat.

However, there is an important caveat here: if cultured meat disrupts the conventional production sector, farm animals will be considerably less numerous, and possibly even disappear. Therefore, some view the drastic reduction and potential disappearance of farm animals as a "curse". There is no doubt that this can generate an immense societal and cultural shock. Animal farming has been common for over 9000 years, and is part of the history of humanity and of our relationship with nature and the animal kingdom. Many claim that farm animals benefit from their interaction with humans. This caveat is reminiscent of an old argument, known as the "logic of the larder", whereby we do animals a favor by producing and eating them because otherwise they would not exist (Salt 1917).

However, this argument is problematic for several reasons. We note first that from a pure utilitarian perspective this is a curse only if living for an animal would be better than not living. Yet, many scholars believe that many farm animal lives are not worth living because of the poor rearing conditions (Matheny 2003; Shaefer and Safulescu 2014; Gosseries and 
Meijers 2019). ${ }^{18}$ Second, as initially emphasized by Salt (1917) and discussed by Hopkins and Dacey (2008) and others, the extent to which we might have moral reasons to bring an animal into existence is a difficult metaphysical question. Non-existent creatures do not have interests, and thus cannot be objects of moral obligation. Hence the "logic of the larder" is inconclusive. Third, this logic is fundamentally based on a murderous relationship to animals (Burgat 2019), and can hardly be presented as a desirable moral goal. Relatedly, there is an inconsistency when arguing that cultured meat might destroy our relationship to animals: if we do value significantly the link with farm animals beyond the production of meat, then this link should be preserved even if animals are not used anymore to produce meat. And if not, this means that we do not consider farm animals beyond the commercial value of their flesh.

Furthermore, we must emphasize that farm animals need not disappear, as we may imagine another destiny for them, such as for the few who nowadays live in animal sanctuaries. Along this line, Kymlicka and Donaldson (2011) envision a vegan world in which we consider farm animals differently: domesticated animals should not be our food or our property but instead our neighbors, and we should warrant them no less than citizenship. Moreover, note that cultured meat might never be fully free from animals, as the cells used in the production process must be taken from somewhere. That is, some animals may likely always be needed in order to provide the cells to produce cultured meat. Hence, the complete disappearance of farm animals is not likely, even under an extreme scenario under which all meat would be produced in vitro.

Another issue concerns wild animals. Again, animal farming uses a large amount of land, which has a significant impact on wildlife populations. Animal farming is a major source of loss of biodiversity (Machovina et al. 2015). It has been estimated, for instance, that animal farming is responsible for more than $85 \%$ of the Amazonian deforestation (Godfray et al. 2018). Likewise, the population densities of wild animals on agricultural land are typically lower than those in forests. For instance, Gaston et al. (2003) estimate that "typical" bird densities per square kilometer are 300 in croplands, 375 in pasture, 800 in conifer forests, and 2,500 in tropical forests. Specifically, less animal farming is expected to drastically increase the number of wild animals. Hence, the "logic of the larder" appears to be incomplete at best, since it must account for the corresponding increase in the number of wild birds and mammals on Earth.

What about animal suffering? ${ }^{19}$ As put forward by Bentham (1780) and many other philosophers, the suffering of an animal, and more generally its "sentience", justifies moral consideration. There is little doubt that animals do have the capacity to suffer, as shown through neuroimaging for instance (Da Silva and Seminowicz 2019), and that animal farming generates a high degree of suffering to billions of animals every year. As we said above, many painful practices, such as castration without anesthesia, dehorning, tail docking, teeth clipping, beak trimming, and early mother separation are widespread (Bonnet et al. 2020). To this, we must add the suffering due to a high degree of confinement whilst living, and during transport to slaughter. Moreover, animals probably suffer emotionally through (e.g.)

\footnotetext{
18 Espinosa and Treich (2020) find that survey participants believe that the life of broilers is not worth living under common (i.e., intensive) rearing conditions in France.

19 As is common in philosophy, we purposely separate here the discussion of life/death from that of suffering.
} 
distress, anxiety or boredom. ${ }^{20}$ Animal suffering is in fact consubstantial with essentially every form of animal farming.

Nevertheless, what about cultured meat? In all likelihood, due to the lack of a nervous system, cultured cells should be free from any type of pain. Further, these cells cannot constitute a sentient being in any conceivable form during the process (Shaefer and Safulescu 2014). This means that no sentient animal is produced, hurt or even involved in the manipulation and proliferation of cultured cells. The only procedure that can generate pain concerns the biopsies on animals to collect the cells in the early stage of the production process, but this pain is arguably trivial compared to the usual pain inflicted on farm animals. ${ }^{21}$ To date, we are not aware of any solid proposal arguing that cultured meat may not drastically decrease animal suffering in this world.

Cultured meat is a breakthrough innovation and it raises various moral issues. Here, we have discussed only a few. For the sake of brevity, in Table 1, we summarize some other moral objections to cultured meat, as well as possible corresponding responses. These arguments are taken from Hopkins and Dacey (2008) and Shaefer and Safulescu (2014), and we present them here as succinctly as possible. We recommend the reader to go directly to these sources for a more precise and detailed presentation. Hence, building on these early works in philosophy and on the discussion above, cultured meat does not appear to be particularly problematic in a moral sense. We conclude that it likely constitutes a moral improvement compared to conventional meat. Obviously, more work on the moral aspects will certainly arise as the innovation develops, and we emphasize that this is only a temporary conclusion.

Finally, we note that cultured meat raises moral but also very practical issues in terms of religion. As explained by Hamdan et al. (2017) and Chriki and Hocquette (2020), it is not clear for Islam/Judaism if cultured meat is halal/kosher. Some religious authorities say that it can only be considered for consumption if the original cells were taken from an animal slaughtered in a way consistent with religious practices (i.e., without stunning, etc.). However, others consider that the animals lose their original identity so that the obtained meat cannot be forbidden for consumption. Hence, another view is that the process is so different from the traditional growth of meat that it may be defined as consistent with religious practice, even where traditional meat would not (Kenigsberg and Zivotofsky 2020). Note finally that cultured meat also raises questions for the religions that tend to encourage vegetarianism, such as Buddhism or Jainism. It is not clear how these religions will react to the innovation.

\section{Some Regulatory Issues}

As a novel product, cultured meat requires a regulatory framework. Since consumer confidence about the safety of the product is critical, this regulatory approval will also be critical for consumers' acceptance in general. In Europe, the regulatory pathway for commercialization is known. Indeed, the revised EU Novel Food entered into force in 2018 and was followed by a series of implementation acts and European Food Safety Authority

\footnotetext{
${ }^{20}$ Recent scientific research about farm animals points out that they are cognitively, emotionally and socially complex, as is the case for chicken for instance (Marino 2017).

21 Moreover, startups are apparently trying to painlessly obtain cells from (as some examples) eggs, feathers or umbilical cords (personal communication).
} 
Table 1 Some moral objections to cultured meat and responses. Source: Hopkins and Dacey (2008) and Shaefer and Safulescu (2014)

Moral objection to cultured meat

Response

A lack of moral respect: We lack moral respect for animals by commodifying or instrumentalizing them

The conventional meat industry is worse because it treats the entire animal as a mere product. Cultured meat only instrumentalizes cells and tissues

Animal integrity: Animals should not be biotechnologically altered

The animal that provides the cells is not altered and the resulting tissue culture is not a new type of organism. The meat industry does alter animals (e.g., genetically)

Wrong moral motivation: Cultured meat is motivated by selfishness when we should be virtuous

Our main goal is not to boost our own moral selfregard and virtue, but to relieve animal suffering. Further, people can choose, and thus vote with their conscience

Delay moral change: Hoping for a technological fix

If appeals against animal suffering are working, will make people more at ease with meat-eating now they should continue to work when animals suffer, whether or not this suffering may be obviated in the future

Respect for nature: We must respect and accept what nature gives. Seeking a technological fix is arrogant

What is natural is not the same as what is good. Our desire to be humble should not trump our desires to reduce animal suffering

Cannibalism: Cultured meat opens the door for the consumption of human flesh

Cultured meat would not involve two main moral issues with cannibalism: human killing and corpse desecration. Consumption of human cultured meat could be banned

(EFSA) guidelines. The EU authorization application procedure includes a risk assessment stage, and requires that cultured animal products and production are proven safe by the applicants (usually companies). In the US, the Food and Drug Administration (FDA) and the Department of Agriculture (USDA) announced in 2018 that they will both share the regulatory oversight. FDA will oversee the cell growth, cell banks and cell differentiation stages, while USDA will oversee the production and labeling stages. See Post et al. (2020) for a detailed description and comparison of EU and US regulatory frameworks.

Cultured meat is a new product and, as such, is subject to scientific uncertainty. Some argue that our societies should invest in this product, at the least to see if any benefits may be realized (Stephens et al. 2018). As with all possibly disruptive innovations, it might have many unexpectedly positive, as well as negative, consequences. One critical issue here concerns the optimal timing of the market authorization relative to a better scientific understanding. We are in the realm of the precautionary principle, with two opposing forces. On the one hand, there is the danger to allow a potentially toxic product on the market with negative and possibly irreversible consequences. On the other hand, there is the danger of being too cautious, and delaying beneficial innovations (Gollier and Treich 2003).

Weeds (2002) emphasizes an additional economic force that warrants more precaution. Since there is a high premium promised to the first mover under a winner-takes-all patent system, innovative firms fear the risk of preemption and have an incentive to introduce their products on the market too early. However, we must also account for another subtle effect: higher standards of regulation could imply that fewer firms access the market. Thus, there is an additional regulatory tradeoff: a stringent regulatory approval process enhances food safety, but at the cost of increasing market power (Harhoff et al. 2001). Novel regulatory questions may also arise. For instance, if cultured meat and conventional meat become 
barely distinguishable, they might be fraudulently substituted in the production or retail stage, which may require advanced tracker technologies to detect the fraud.

Governments also have a central role to play in the funding of R\&D on cultured meat. There are several reasons justifying more public support to radical innovations (such as cultured meat) rather than incremental innovations. First, as we said above, a radical innovation is more risky, and likely involves more information asymmetry, so that private financial markets may imperfectly manage these frictions. Second, there could be coordination issues since several innovators may be needed to push the knowledge frontier and make the market profitable, but no single company wants to make the early necessary investments. Third, the radical innovators may lack the network to naturally obtain the visibility and political influence necessary to obtain public funds. Moreover, let us add that the government also plays a role in the determination of the laws for intellectual property protection. Here, the overall tradeoff is well known: low protection discourages innovations, but high protection generates monopoly power and discourages innovation spillover (Boldrin and Levine 2008).

A central additional point concerns how R\&D policy may help manage externalities. Indeed, there is also a rationale for regulators to fund fundamental research because it is unlikely that startups fully account of all positive long-term societal externalities. In a context of environmental externalities, and in addition to the implementation of taxes on conventional meat, there is indeed a rationale for the government to provide subsidies to boost greener companies' research efforts in the early stages, as is the case in other domains, such as energy. A particular reason to do so is because market size effects, and the initial productivity advantage of dirty inputs, would mechanically direct innovation and production to that sector, further contributing to environmental degradation. This relates to the "building on the shoulders of giants" effect (Acemoglu et al. 2012). As a result, specific innovation policies need to be in place-at least for a temporary period-because once green technologies are sufficiently advanced, research would be directed towards these technologies without further government intervention.

One specific issue already extensively discussed at a policy and political level, is what name to give to cultured meat. In this domain, political lobbying is already active. It is well known that several jurisdictions have passed "food libel" or "ag-gag" laws repressing animal food criticism and investigations. Both in the US and the EU, new laws have also been enacted limiting the use of words such as "steak", "milk" or "butter" for plant-based protein alternatives. In the case of cultured meat, similar labeling issues have already been raised while the product is not yet even commercialized. For instance, the US Cattlemen's Association (USCA) submitted a petition to USDA in 2018 asking them to establish meat labeling requirements that exclude products not derived directly from animals that have been raised and slaughtered.

The advanced purpose of these laws and petitions is to prevent consumers from being misled. There is a basic economic rationale that accompanies this: if consumers cannot tell whether or not a product is meat, the "lemons" problem is aggravated, which can drive out of the market the best products and eventually reduce consumers' welfare. Interestingly, Van Loo et al. (2020) find that consumers themselves are strongly opposed to allowing the plant and cultured meat alternatives to use the label "beef". ${ }^{22}$ However, there is

\footnotetext{
22 We note, however, that van Loo et al.'s result is based on a question where participants are forced to choose 'yes' or 'no', whilst other data indicates that most consumers have no strong opinion on this; see, e.g., https://www.datasmoothie.com/@surveygoo/food-followup/; (we thank a reviewer for this point).
} 
no evidence as far as we are aware that consumers are confused with existing labeling of meat alternative products. Moreover, the confusion seems even less likely in the case of cultured meat, since the marketing strategy of cultured meat producers is precisely based on the fact that the product is not meat. So, if consumers are unlikely to be confused: what is the meat sector lobbying against? Perhaps this is because the term "meat" tells something about what consumers can expect in terms of how the product should be cooked and served. Consumers may (perhaps subconsciously) associate other positive properties to the product, such as taste or nutritional value. That is, the term "meat" may provide a feeling of familiarity and continuity to the consumer for a novel—and in reality-very different product, such as cultured meat.

Finally, we stress that this discussion raises a range of political economy issues. We have emphasized that the attitude of politicians will be instrumental in facilitating the development of cultured meat. As is well known, the (animal) farming sector is politically very powerful, and should on average react negatively to the innovation since it wants to protect its market from competition. As we have commented in this section, this reaction may include lobbying in order to influence politicians to enact laws unfavorable to cultured meat and to limit funding for the innovation. The intensity of the political reaction, however, is expected to decrease if the conventional sector is associated with the production of cultured meat, for instance, because it has a financial stake in startups or because it provides the nutrients that feed the cultured cells. One major political uncertainty remains, which concerns the ability of the conventional sector to manufacture doubt about the innovation in order to reduce its acceptance. The history of GMO that was widely rejected in the EU by the public is a case in point (Mohorčich and Reese 2019).

\section{Conclusion}

It is widely recognized that conventional meat production generates important negative externalities. It contributes significantly to climate change, and various forms of local pollution. It uses a great deal of water and land. Animal farming is also a major driver of deforestation, loss of biodiversity and epidemics. However, the regulation of animal farming and meat consumption seems limited compared to the large negative externalities it generates (Bonnet et al. 2020; Tschofen et al. 2019). Instead, the conventional meat sector is heavily subsidized, as exemplified by the Common Agricultural Policy in Europe. In this economic and political context, given that many consumers do not want to change their food habits, and given that the demand for meat is expected to grow in the developing world, it appears that cultured meat provides a serious, perhaps the most serious, alternative to be able to significantly reduce the deleterious impacts of meat production and consumption. Moreover, this innovation can significantly reduce the immense suffering of farm animals. We now conclude with a few open questions and challenges for the future.

In this paper, we have mostly compared cultured and conventional meat. However, some food experts view plant-based options as the main competitor on the future protein market (AT Kearney 2019). Indeed, interest in and the consumption of plant-based products has recently increased markedly. Investments in plant-based companies are much more important than in cultured meat companies (Cameron and O'Neill 2019). From an environmental viewpoint, plant-based food options seem to systematically dominate conventional meat, as well as the cultured meat alternatives (see Fig. 2; Smetana et al. 2015; World Economic Forum 2019). Hence, it does not seem acceptable to wait for cultured meat to address the 
environmental burden of animal agriculture, and a large shift toward plant-based food seems necessary in the short term. However, the key difficulty is to reproduce the taste of meat with plants only. Recent plant-based products, such as the popular burgers from Beyond Meat or Impossible Foods, have made significant progress, but they are also criticized for being ultra-processed food with the associated health concerns.

The literature emphasizes that a central issue regarding the development of cultured meat is consumers' acceptance. However, as we have argued, it is important to realize that it is very difficult today to anticipate future consumers' acceptance. Moreover, cultured meat may find a market beyond standard food markets. It could provide food for pets (Oven et al. 2020), such as dogs or cats, since acceptability is likely less of an issue for most pet owners. Early (human or pet) adopters may then help progressively build trust for these products in society. New production techniques may also generate non-food products, such as cultured leather or collagen. Other products of cellular agriculture, such as fermentationbased products, may deliver marketable animal analog products, such as milk or eggs, in a shorter timeframe compared to cultured meat because they are essentially an extension of common production methods (Waschulin and Specht 2018). Additionally, one cannot exclude that cultured-cell techniques may help generate other benefits such as a reduction of poaching: what would happen for instance if it were possible to produce (e.g.) cultured ivory undistinguishable from real material $?^{23}$ It is unclear, however, if the success (or failure) of these parallel innovations will help the development of cultured meat.

Moreover, we have emphasized several political issues. The efficiency of the conventional meat sector lobbying against cultured meat will depend on the evolution of the context in which it occurs; in particular, the overall public awareness of (meat induced) environmental externalities, such as climate change. Additionally, information technologies render the intensive rearing conditions of animals increasingly visible, which are becoming more and more socially unacceptable. Policy makers may in turn feel pressure from society to regulate and reduce public support to meat production and consumption, and to stimulate the emergence of solutions. This pressure may be high in some countries such as Singapore where novel technologies like cultured meat may help ensure food self-sufficiency. In that context, the support to cultured meat may also increase worldwide. However, a portion of the public may reject the whole trend of industrial and innovative agriculture, instead favoring eco-friendly, local and low-scale forms of agriculture. A related open question concerns the reaction to cultured meat of environmentalist NGOs and political green parties. This also explains why the environmental impact of the innovation is probably instrumental to its acceptance and development.

Finally, we conclude with some remarks about the main purpose of this paper, which is to stimulate some economic research on cultured meat. During the discussion, we have identified several research topics for economists. Let us just cite three. First, it is central to better understand the drivers of the demand for cultured meat, in particular by using nonhypothetical preference elicitation methods. One essential question is the following: which consumers will buy the novel food, and what will be the induced food substitution effects? Second, we have emphasized that cultured meat should significantly reduce environmental impacts, in particular through a large reduction in land use. Its production may however require a lot of energy, thus linking issues of food, agriculture and land use with those of climate, the environment and energy. Studying properly these links and trade-offs may

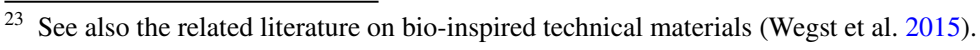


require a full-fledged economic analysis. Third and finally, a central question concerns the role of the regulator to stimulate the emergence and development of the innovation. So far, this role has been limited. However, due to the high potential for positive external impacts, public intervention is required. Yet, the optimal form of intervention is unclear, in particular given existing market and regulatory failures in the agricultural sector, and the high uncertainties. As a second-best, we suggested that the regulator should support R\&D on cultured meat, but more economic research is needed on this issue.

Acknowledgements The author acknowledges the editor, four anonymous reviewers, Tom Bry-Chevalier, David Chauvet, Alice Di Concettto, David Hémous, Vincent Réquillart, Nathalie Rolland, Tristan Roth, Natalie Rubio, Lea Stapper, Cor van der Weele and the participants at the 2019 Paris conference entitled "Agriculture cellulaire et alternatives aux produits lacto-ovo-carnés" for useful discussions, as well as research support from ANR under grant ANR-17-EURE-0010 (Investissements d'Avenir program), the Innov program (INRAE), and the FDIR chair at the Toulouse School of Economics (TSE-Partnership).

\section{Declarations}

Conflict of interest The author declares no conflict of interest.

\section{References}

Acemoglu D, Aghion P, Bursztyn L, Hémous D (2012) The environment and directed technical change. Am Econ Rev 102:131-166

Acemoglu D, Akcigit U, Celik MA (2020) Radical and incremental innovation: the role of firms, managers and innovators. AEJ Macroecon (forthcoming)

Afshin A et al (2019) Health effects of dietary risks in 195 countries, 1990-2017: a systematic analysis for the global burden of disease study 2017. Lancet 393(10184):1958-1972

Alexander P et al (2017) Could consumption of insects, cultured meat or imitation meat reduce global agricultural land use? Glob Food Secur 15:22-32

Akcigit U, Kerr WR (2018) Growth through heterogeneous innovations. J Polit Econ 126(4):1374-1443

Asioli D, Bazzani C, Nayga RM (2020) Consumers' valuation for lab produced meat: an investigation of naming effects In: mimeo

AT Kearney (2019) How will cultured and meat alternatives disrupt the agricultural and food industry?

Atkin D, Colson-Sihva E, Shayo M (2018) How do we choose our identity? A revealed preference approach using food consumption In: mimeo

Bar-on YM, Philips R, Milo R (2018) The biomass distribution on earth. Proc Natl Acad Sci 115:6506-6511

Barjavel R (1943) Ashes, ashes (French: Ravage). Doubleday, Garden City, New York

Bègue L, Treich N (2019) Immediate and 15-week correlates of individual commitment to a "Green Monday" national campaign fostering weekly substitution of meat and fish by other nutrients. Nutrients 7:1694

Bentham J (1780) An introduction to the principles of morals and legislation. https://www.econlib.org/libra ry/Bentham/bnthPML.html

Boldrin M, Levine DK (2008) Against intellectual monopoly. Cambridge University Press, Cambridge

Bonnet C, Bouamra Z, Réquillart V, Treich N (2020) Viewpoint: how to regulate meat consumption to improve health, the environment and animal welfare? Food Policy 97:101847

Bouvard V et al (2015) Carcinogenicity of consumption of red and processed meat. Lancet Oncol 16(16): $1599-1600$

Broad GM (2019) Plant-based and cell-based animal product alternatives: an assessment and agenda for food tech justice. Geoforum 107:223-226

Broom D (2014) Sentience and animal welfare. CABI Publishing, Wallingford

Bryant C, Barnett J (2018) Consumer acceptance of cultured meat: a systematic review. Meat Sci 143:8-17

Bryant C, Dillard C (2019) The impact of framing on acceptance of cultured meat. Front Nutr 6:103

Bryant CJ, Anderson JE, Asher KE, Green C, Gasteratos K (2019a) Strategies for overcoming aversion to unnaturalness: the case of clean meat. Meat Sci 154:37-45 
Bryant C, Szejda K, Parekh N, Deshpande V, Tse B (2019b) A survey of consumer perceptions of plantbased and clean meat in the USA, India, and China. Front Sustain Food Syst. https://doi.org/10.3389/ fsufs.2019.00011

Bryant C, Barnett J (2020) Consumer acceptance of cultured meat: an updated review (2018-2020). Appl Sci 10:5201

Burgat F (2019) Will symbolic sacrifice triumph over real sacrifice? A structuralist hypothesis on the role of meat and milk substitutes. Philos Today (forthcoming)

Cameron B, O’Neill S (2019) State of the industry report: cell-based meat. The Good Food Institute, Washington

Carlsson F, Kataria M, Lampi E (2021) How much does it take? Willingness to switch to meat substitutes. In: mimeo

Catts O, Zurr I (2007) Semi-living art. In: Kac E (ed) Signs of life: bio art and beyond. MIT Press, Cambridge, pp 231-247

Chriki S, Hocquette J-F (2020) The myth of cultured meat: a review. Front Nutr 7:7

Da Silva JT, Seminowicz DA (2019) Neuroimaging of pain in animal models: a review of recent literature. Pain Rep 4(4):e732

Desjeux Y, Dupraz P, Kuhlman T, Paracchini ML, Michels R, Maigné E, Reinhard S (2015) Evaluating the impact of rural development measures on nature value indicators at different spatial levels: application to France and The Netherlands. Ecol Ind 59:41-61

Dillard-Wright DB (2013) In vitro meat/laboratory meat. In: Encyclopedia of food and agricultural ethics, vol 307

Espinosa R, Treich N (2020) Animal welfare: Antispeciesism, veganism and a "life worth living". Soc Choice Welfare (forthcoming)

Espinosa R, Tago D, Treich N (2020) Infectious diseases and meat production. Environ Resour Econ 4:1-26

Foley JA et al (2011) Solutions for a cultivated planet. Nature 478:337-342

Ford BJ (2013) Impact of cultured meat on global agriculture. World Agriculture, New York

Gaston K, Blackburn T, Goldewijk K (2003) Habitat conversion and global avian biodiversity loss. Proc Biol Sci 270(1521):1293-1300

Gaydhane MK, Mahanta U, Sharma CS, Khandelwal M, Ramakrishna S (2018) Cultured meat: state of the art and future. Biomanuf Rev 3:1

Gasteratos K (2019) 90 Reasons to consider cellular agriculture. Harvard Library, Harvard

Godfray C et al (2018) Meat consumption, health and the environment. Science 361:6399

Gollier C, Treich N (2003) Decision-making under scientific uncertainty: the economics of the precautionary principle. J Risk Uncertain 27:77-103

Gosseries A, Meijers T (2019) Animal population ethics. In: Mimeo

Graça J, Calheiros MM, Oliveira A (2015) Attached to meat? (Un)Willingness and intentions to adopt a more plant-based diet. Appetite 95:113-212

Hayek MN, Harwatt H, Ripple WJ et al (2020) The carbon opportunity cost of animal-sourced food production on land. Nat Sustain. https://doi.org/10.1038/s41893-020-00603-4

Hamdan M, Post M, Ramli MA, Amin M (2017) Cultured meat in Islamic perspective. J Relig Health. https://doi.org/10.1007/s10943-017-0403-3

Haskel J, Westlake S (2018) Capitalism without capital. Princeton University Press, Princeton

Hestermann N, Le Yaouanq Y, Treich N (2020) An economic model of the meat paradox. Eur Econ Rev 129:103569

Hocquette A et al (2015) Educated consumers don't believe artificial meat is the solution to the problems with the meat industry. J Integr Agric 14(2):273-284

Hocquette J-F (2016) Is in vitro meat the solution for the future? Meat Sci 120:167-176

Hopkins PD, Dacey A (2008) Vegetarian meat: could technology save animals and satisfy meat eaters? J Agric Environ Ethics 21:579-596

Howard PH (2017) Corporate concentration in global meat processing: the role of government subsidies. In: Mimeo

INRA (2017) Rôle, Impacts et Services issus des Elevages Européens, Expertise collective INRA

IPES-FOOD (2017) Too big to feed: exploring the impacts of mega-mergers, concentration, concentration of power in the agri-food sector. www.ipes-food.org

IPBES (2019) Summary for policymakers of the global assessment report on biodiversity and ecosystem services of the Intergovernmental Science-Policy Platform on Biodiversity and Ecosystem Services (in press)

IPCC (2019) Climate change and land: an IPCC special report on climate change, desertification, land degradation, sustainable land management, food security, and greenhouse gas fluxes in terrestrial ecosystems (in press) 
Iyengar SS, Lepper MR (2000) When choice is demotivating: can one desire too much of a good thing? J Pers Soc Psychol 79(6):995-1006

Jones KE et al (2008) Global trends in emerging infectious diseases. Nature 451:990-993

Kenigsberg JA, Zivotofsky AZ (2020) A Jewish religious perspective on cellular agriculture. Front Sustain Food Syst 3:128

Kirsch A, Kroll J-C, Trouvé A (2017) Aides directes et environnement : la politique agricole commune en question. Économie Rurale 359:121-139

Kymlicka W, Donaldson S (2011) Zoopolis: a political theory of animal rights. Oxford University Press, Oxford

Laxminarayan R et al (2013) Antibiotic resistance-the need for global solutions. Lancet Infect Dis 13:1057-1098

Loughnan S, Haslam N, Bastian B (2010) The role of meat consumption in the denial of moral status and mind to meat animals. Appetite 55(1):156-159

Lynch J, Pierrehumbert R (2019) Climate impacts of cultured meat and beef cattle. Front Sustain Food Syst $3: 5$

Machovina B, Feeley KJ, Ripple WJ (2015) Biodiversity conservation: the key is reducing meat consumption. Sci Total Environ 536:419-431

Marino L (2017) Thinking chickens: a review of cognition, emotion, and behavior in the domestic chicken. Anim Cogn 20:127-147

Markandya A, Taylor T, Longo A, Murty MN, Murty S, Dhavala K (2008) Counting the cost of vulture decline-an appraisal of the human health and other benefits of vultures in India. Ecol Econ 67:194-204

Matheny G (2003) Least harm: a defense of vegetarianism from Steven Davis's omnivorous proposal. J Agric Environ Ethics 15:505-511

Mattick CS, Landis AE, Allenby BR, Genovese NJ (2015) Anticipatory life cycle analysis of in vitro biomass cultivation for cultured meat production in the United States. Environ Sci Technol 49(19):11941-11949

McDonald BNJ, Vivalt E (2018) Effective strategies for overcoming the naturalistic heuristic: experimental evidence on consumer acceptance of "clean" meat. In: Mimeo

Moerbeek H, Casimir G (2005) Gender differences in consumers' acceptance of genetically modified foods. Int J Consum Stud 29:308-318

Mohorčich J, Reese J (2019) Cell-cultured meat: lessons from GMO adoption and resistance. Appetite 143:104408

Norwood FB, Lusk JL (2011) Compassion, by the pound: the economics of farm animal welfare. Oxford University Press, Oxford

Nyborg K et al (2016) Social norms as solutions. Science 354:42-43

O’Neill J (2015) Antimicrobial in agriculture and the environments. Rev Antimicrob Res 7:1728

Orzechowski A (2015) Artificial meat? Feasible approach based on the experience from cell culture studies. J Integr Agric 14:217-221

Oven A, Ward E, Bethencourt R (2020) The clean pet food revolution. Lantern Books, Brooklyn

Pe'er G. et al (2014) EU agricultural reform fails on biodiversity. Science 344:1090-1092

Pieper M, Michalke A, Gaugler T (2020) Calculation of external climate costs for food highlights inadequate pricing of animal products. Nat Commun 11:6117

Piazza J et al (2015) Rationalizing meat consumption. the 4Ns. Appetite 91:114-128

Poore J, Nemecek T (2018) Reducing food's environmental impacts through producers and consumers. Science 360:987-992

Porcher J (2019) Cause Animale, Cause du Capital. Editions Le Bord de l'Eau

Post MJ (2014) Cultured beef: medical technology to produce food. J Sci Food Agric 94(6):1039-1041

Post MJ, Levenberg S, Kaplan DL et al (2020) Scientific, sustainability and regulatory challenges of cultured meat. Nature Food 1:403-415

Ready RC, Abdalla CW (2005) The amenity and disamenity impacts of agriculture: estimates from a hedonic pricing model. Am J Agric Econ 87:314-326

Reese J (2018) The end of animal farming. Beacon Press, Boston

Rohr JR et al (2019) Emerging human infectious diseases and the links to global food production. Nat Sustain 2:445-456

Rolland N, Markus CR, Post MJ (2020) The effect of information content on acceptance of cultured meat in a tasting context. Plos ONE

Rothgerber H (2013) Real men don't eat (vegetable) quiche: masculinity and the justification of meat consumption. Psychol Men Masculin 14:363-375 
Rubio NR, Xiang N, Kaplan DL (2020) Plant-based and cell-based approaches to meat production. Nat Commun 11:6276

Ruby MB (2012) Vegetarianism. a blossoming field of study. Appetite 58:141-150

Ruby MB, Heine SJ (2011) Meat, morals, and masculinity. Appetite 56:447-450

Salt HS (1917) The logic of the larder. http://www.animal-rights-library.com/texts-c/salt02.pdf

Schaefer GO, Savulescu J (2014) The ethics of producing in vitro meat. J Appl Philos 31(2):188-202

Schütz L et al (2018) Improving crop yield and nutrient use efficiency via biofertilization-a global metaanalysis. Front Plant Sci 8:2204

Searchinger TD, Wirsenius S, Beringer T, Dumas P (2018) Assessing the efficiency of changes in land use for mitigating climate change. Nature 564:249-253

Sebo J (2018) The ethics and politics of plant-based and cultured meat. Ateliers Ethique. Ethics Forum 1:159-183

Siegrist B, Sutterlin B, Hartmann C (2018) Perceived naturalness and evoked disgust influence acceptance of cultured meat. Meat Sci 139:213-219

Slade P (2018) If you build it, will they eat it? Consumer preferences for plant-based and cultured meat burgers. Appetite 125:428-437

Smetana S, Mathys A, Knoch A, Heinz V (2015) Meat alternatives: life cycle assessment of most known meat substitutes. Int J Life Cycle Assess 20:1254-1267

Sneeringer S (2009) Does animal feeding operation pollution hurt public health? A national longitudinal study of health externalities identified by geographic shifts in livestock production. Am J Agric Econ 91:124-137

Specht L (2020) An analysis of culture medium cost and production volumes for cultivated meat. The Good Food Institute. Technical report

Springmann M, Godfray HCJ, Rayner M, Scarborough P (2016) Analysis and valuation of the health and climate change co-benefits of dietary change. Proc Natl Acad Sci 113(15):4146-4151

Springmann M, Spajic L, Clark MA, Poore J et al (2020) The healthiness and sustainability of national and global food based dietary guidelines: modelling study. BMJ 370:m2322

Stephens N et al (2018) Bringing cultured meat to market: technical, socio-political, and regulatory challenges in cellular agriculture. Trends Food Sci Technol 78:155-166

TAPPC (2020) Aligning food pricing policies with the European Green Deal. True pricing of meat and dairy in Europe, including CO2 Costs. True Animal Protein Price Coalition

The Economist (2018) The retreat from meat: Why people in rich countries are eating more vegan food

Tschofen P, Azevedo IL, Muller NZ (2019) Fine particulate matter damages and value added in the US economy. Proc Natl Acad Sci 116(40):19857-19862

Tucker CA (2014) The significance of sensory appeal for reduced meat consumption. Appetite 81:168-179

Tuomisto HL, Hodge ID, Riordan P, Macdonald DW (2012) Does organic farming reduce environmental impacts? A meta-analysis of European research. J Environ Manag 112:309-320

Tuomisto HL, Teixeira de Mattos MJ (2011) Environmental impacts of cultured meat production. Environ Sci Technol 45:6117-6123

Tuomisto HL, Ellis M, Haastrup P (2014) Environmental impacts of cultured meat: alternative production scenario. In: 9th International conference on life cycle assessment in the agri-food sector, San Francisco, CA

Tuomisto HL (2018) The eco-friendly burger. EMBO Reports 20, 1, First published: 14 December 2018

Van der Weele C, Tramper J (2014) Cultured meat: Every village its own factory? Trends Biotechnol 32:294-296

Van der Weele C, Driessen C (2019) How normal meat becomes stranger as cultured meat becomes more normal; Ambivalence and ambiguity below the surface of behavior. Front Sustain Food Syst 3:2571-2581

Van Loo EJ, Caputo V, Lusk JL (2020) Consumer preferences for farm-raised meat, lab-grown meat, and plant-based meat alternatives: Does information or brand matter? Food Policy 95:101931

Vergnaud AC et al (2010) Meat consumption and prospective weight change in participants of the EPICPANACEA study. Am J Clin Nutr 92:398-407

Vialles N (1988) La viande ou la bête. Terrain 10:86-96

Vivalt E, MacDonald B (2018) The impact of new products on ethical beliefs. In: Mimeo

Wang X et al (2019) The effects of mulch and nitrogen fertilizer on the soil environment of crop plants, 1st edn. Elsevier, Amsterdam

Waschulin V, Specht L (2018) Cellular agriculture: an extension of common production methods for food. The Good Food Institute. Technical report

Weeds H (2002) Strategic delay in a real options model of R\&D competition. Rev Econ Stud 69:729-747

Wegst U et al (2015) Bioinspired structural materials. Nat Mater 14:23-36 
Weinrich R, Strack M, Neugebauer F (2020) Consumer acceptance of cultured meat in Germany. Meat Sci 162:107924

Wilks M, Phillips CJ (2017) Attitudes to in vitro meat: a survey of potential consumers in the United States. PLoS ONE 12(2):e0171904

Willett W et al (2019) Food in the anthropocene: the EAT-lancet commission on healthy diets from sustainable food systems. Lancet 393:447-492

Wolk A (2017) Potential health hazards of eating red meat. J Int Med 281:106-122

World Economic Forum (2019) Meat: the future series-alternative proteins. White paper. Prepared by the Oxford Martin School

Young JF, Skrivergaard S (2020) Cultured meat on a plant-based frame. Nat Food

Zabraska M (2016) Meathooked: the history and science of our 25-million-year obsession with meat. Basic Books, New York

Publisher's Note Springer Nature remains neutral with regard to jurisdictional claims in published maps and institutional affiliations. 